\title{
A Type 2 Deiodinase-Dependent Increase in Vegfa Mediates Myoblast-Endothelial Cell Crosstalk During Skeletal Muscle Regeneration
}

\author{
Xingxing An, ${ }^{1,2}$ Ashley Ogawa-Wong, ${ }^{2}$ Colleen Carmody, ${ }^{2}$ Raffaele Ambrosio, ${ }^{3}$ \\ Annunziata Gaetana Cicatiello, ${ }^{4}$ Cristina Luongo, ${ }^{5}$ Domenico Salvatore, ${ }^{5,6}$ Diane E. Handy, \\ P. Reed Larsen, ${ }^{2}$ Simone Magagnin Wajner, ${ }^{2,8}$ Monica Dentice, ${ }^{4}$ and Ann Marie Zavacki ${ }^{2}$
}

Background: The type 2 deiodinase (DIO2) converts thyroxine to 3,3',5-triiodothyronine (T3), modulating intracellular T3. An increase in DIO2 within muscle stem cells during skeletal muscle regeneration leads to T3dependent potentiation of differentiation. The muscle stem cell niche comprises numerous cell types, which coordinate the regeneration process. For example, muscle stem cells provide secretory signals stimulating endothelial cell-mediated vascular repair, and, in turn, endothelial cells promote muscle stem differentiation. We hypothesized that Dio2 loss in muscle stem cells directly impairs muscle stem cell-endothelial cell communication, leading to downstream disruption of endothelial cell function.

Methods: We assessed the production of proangiogenic factors in differentiated $\mathrm{C} 2 \mathrm{C} 12$ cells and in a $\mathrm{C} 2 \mathrm{C} 12$ cell line without Dio2 (D2KO C2C12) by real-time quantitative-polymerase chain reaction and enzyme-linked immunosorbent assay. Conditioned medium (CM) was collected daily in parallel to evaluate its effects on human umbilical vein endothelial cell (HUVEC) proliferation, migration and chemotaxis, and vascular network formation. The effects of T3-treatment on vascular endothelial growth factor (Vegfa) mRNA expression in $\mathrm{C} 2 \mathrm{C} 12$ cells and mouse muscle were assessed. Chromatin immunoprecipitation (ChIP) identified thyroid hormone receptor (TR) binding to the Vegfa gene. Using mice with a targeted disruption of Dio2 (D2KO mice), we determined endothelial cell number by immunohistochemistry/flow cytometry and evaluated related gene expression in both uninjured and injured skeletal muscle.

Results: In differentiated D2KO C2C12 cells, Vegfa expression was $46 \%$ of wildtype (WT) C2C12 cells, while secreted VEGF was 45\%. D2KO C2C12 CM exhibited significantly less proangiogenic effects on HUVECs. In vitro and in vivo $\mathrm{T} 3$ treatment of $\mathrm{C} 2 \mathrm{C} 12$ cells and WT mice, and ChIP using antibodies against $\mathrm{TR} \alpha$, indicated that Vegfa is a direct genomic T3 target. In uninjured D2KO soleus muscle, Vegfa expression was decreased by $28 \%$ compared with WT mice, while endothelial cell numbers were decreased by $48 \%$. Seven days after skeletal muscle injury, D2KO mice had 36\% fewer endothelial cells, coinciding with an $83 \%$ decrease in Vegfa expression in fluorescence-activated cell sorting purified muscle stem cells.

Conclusion: Dio2 loss in the muscle stem cell impairs muscle stem cell-endothelial cell crosstalk via changes in the T3-responsive gene Vegfa, leading to downstream impairment of endothelial cell function both in vitro and in vivo.

Keywords: thyroid hormone, deiodinase, VEGF, angiogenesis, satellite cell, skeletal muscle

\footnotetext{
${ }^{1}$ Key Laboratory of Transplant Engineering and Immunology, Department of Endocrinology, West China Hospital, Sichuan University, Chengdu, People's Republic of China.

${ }^{2}$ Division of Endocrinology, Diabetes, and Hypertension, Department of Medicine, Brigham and Women's Hospital, Boston, Massachusetts, USA.

${ }^{3}$ IRCCS SDN, Naples, Italy.

Departments of ${ }^{4}$ Clinical Medicine and Surgery and ${ }^{5}$ Public Health, University of Naples "Federico II," Naples, Italy.

${ }^{6}$ CEINGE-Biotecnologie Avanzate Scarl, Naples, Italy.

${ }^{7}$ Cardiovascular Division, Department of Medicine, Brigham and Women's Hospital, Boston, Massachusetts, USA.

${ }^{8}$ Endocrine Division, Hospital de Clinicas de Porto Alegre, Universidade Federal do Rio Grande do Sul, Porto Alegre, Brazil.
} 


\section{Introduction}

$\mathbf{T}$ HYROID HORMONE (TH) REGULATES gene expression through several pathways, including the classical wellstudied genomic pathway, which involves binding to the nuclear thyroid hormone receptor (TR) and also indirectly at the nongenomic level by several different mechanisms (1-3). Genomic TH action can be further fine-tuned by intracellular transport of TH, modulation of TR expression, and TH production and inactivation (4).

TH is essential for skeletal muscle function, controlling both muscle contractility and metabolism (5). In humans, more than 600 genes were modulated by levothyroxine treatment, supporting a broad regulation of the muscle transcriptome by $\mathrm{TH}$ (6). Further, muscle pain and weakness are common symptoms in both hypothyroid and hyperthyroid patients (7-11). Specifically, in hypothyroid muscle, there is a fiber type switch from glycolytic to oxidative, less ATP production, accumulation of glycogen, and increased use of anaerobic pathways, in conjunction with increased serum creatine kinase levels that are suggestive of muscle damage (12-18). Of note, some hypothyroid patients report persistent muscle symptoms up to years after thyroid status is corrected (19).

A significant amount of 3,3',5-triiodothyronine (T3) in the skeletal muscle is derived from the activation of the prohormone thyroxine (T4) to T3 by the type 2 deiodinase (DIO2) (20). In muscle, DIO2 is expressed at low levels in muscle fibers, but it increases in the muscle stem cells during myogenesis and after injury during regeneration to provide additional T3, which enhances differentiation (20-23). Although mice with targeted deletion of the Dio2 gene (D2KO mice) have normal serum T3 levels, these mice have decreased T3 content in their skeletal muscle, which is associated with numerous functional abnormalities, including delayed regeneration after injury and increased muscle weakness and fatigue (24-26).

Muscle stem cells, also known as satellite cells, are necessary for long-term muscle maintenance. These cells are usually quiescent under homeostatic conditions, but after injury satellite cells become activated and proliferate, differentiate, and eventually fuse into myofibers repairing the damaged muscle (27). In addition, there are numerous other cell types in the muscle stem cell niche that interact with the muscle stem cell to coordinate regeneration (28). For example, crosstalk between muscle stem cells and endothelial cells is an important component of muscle repair (29-31). During muscle regeneration, endothelial cells are required to form blood vessels that are necessary to supply nutrients and oxygen. Angiogenesis, the process of producing new blood vessels from pre-existing capillaries, involves proliferation and migration of endothelial cells and remodeling of the extracellular matrix (32). The principal mediator of endothelial cell growth and migration is vascular endothelial growth factor (VEGF) (33). During myoblast differentiation, Vegfa expression is increased, supporting angiogenesis during regeneration $(29,34)$. The VEGF produced by muscle stem cells also attracts endothelial cells in close proximity, and these endothelial cells, in turn, provide factors promoting muscle stem cell quiescence (31). Thus, VEGF is an important coordinator of muscle stem cell-endothelial cell crosstalk in skeletal muscle both under basal conditions and during regeneration after injury.
TH has proangiogenic effects that can be partially attributed to VEGF (35). TH treatment has been shown to enhance Vegfa expression through numerous mechanisms, including directly through the nuclear TR and indirectly through integrin $\alpha \mathrm{v} \beta$, Hif $1 \alpha$, PDGF-Akt, and modulation of steroid production (36-42). Here, we present studies evaluating how a loss of local $\mathrm{T} 3$ production by $\mathrm{DIO} 2$ will affect the interplay between muscle stem cells and endothelial cells. Our data show that the interactions between these two cell types are altered in the absence of Dio2 as a result of changes in the growth factor VEGF. We find that Vegfa is a direct genomic target of T3, and further that Dio2 loss impairs Vegfa expression and VEGF production in the myoblast cell line C2C12 during differentiation. This leads to decreased proangiogenic effects on endothelial cells in vitro. In vivo, $\mathrm{D} 2 \mathrm{KO}$ mice have lower Vegfa and decreased numbers of endothelial cells in their skeletal muscle both under basal conditions and during regeneration after injury. Our data highlight the importance of Dio2 in muscle stem cellendothelial cell crosstalk via regulation of VEGF.

\section{Materials and Methods}

\section{C2C12 cell culture and treatments}

Murine myoblast $\mathrm{C} 2 \mathrm{C} 12$ cells were grown at $37^{\circ} \mathrm{C}$ in a humidified $5 \% \quad \mathrm{CO}_{2}$ atmosphere and maintained in highglucose Dulbecco's Modified Eagle Medium (DMEM) with $20 \%$ fetal bovine serum (FBS) and $1 \%$ penicillinstreptomycin (P-S) (Invitrogen, Carlsbad, CA). Disruption of Dio2 in C2C12 cells using CRISPR/Cas9 (D2KO C2C12) has been previously described (26). To induce differentiation, $\mathrm{C} 2 \mathrm{C} 12$ cells were plated at $10^{4}$ cells/well in 12-well tissue culture plates, grown to $90 \%$ confluence, and finally cultured for five days in differentiation medium containing highglucose DMEM, 2\% horse serum (HS), $1 \% \mathrm{P}-\mathrm{S}$, and $1 \%$ insulin-transferrin-selenium (Invitrogen). During differentiation, conditioned medium (CM) was collected daily, centrifuged at $1000 \mathrm{~g}$ for 10 minutes to remove debris, and stored at $-20^{\circ} \mathrm{C}$ until use. To determine the dose-response of Vegfa to $\mathrm{T} 3 \mathrm{C} 2 \mathrm{C} 12$, cells were differentiated in $\mathrm{TH}$-free differentiation medium supplemented with the indicated T3 dose for four days. To evaluate the effects of T3 supplementation on Vegfa expression in D2KO C2C12 under normal TH conditions cells were differentiated in the presence of additional $30 \mathrm{nM}$ T3 for five days. To assess T3 responsiveness of Vegfa in differentiated $\mathrm{C} 2 \mathrm{C} 12$, cells were differentiated under normal conditions for five days, followed by a 24hour incubation in TH-free differentiation medium; then, they were treated with $\mathrm{TH}$-free differentiation medium plus the indicated T3 dose for 24 hours. TH-free differentiation medium was made by using resin-stripped HS (43).

Hypoxia was induced in differentiating cells for 48 hours either by using a modular hypoxia chamber $\left(1 \% \mathrm{O}_{2}, 5 \% \mathrm{CO}_{2}\right.$, with $\mathrm{N}_{2}$ balance at $37^{\circ} \mathrm{C}$ ) or by treating with $200 \mu \mathrm{M}$ $\mathrm{CoCl}_{2}$ (44).

\section{VEGF measurement by enzyme-linked immunosorbent assay}

VEGF levels in culture medium of $\mathrm{C} 2 \mathrm{C} 12$ cells were measured by using a VEGF Enyzme-Linked Immunosorbent Assay KIT (R\&D Systems, Minneapolis, MN) according 
to the manufacturer's instructions and normalized by DNA content. DNA was measured by using the Cyquant cell proliferation kit (Molecular Probes, Eugene, OR) following the manufacturer's instructions.

\section{Human umbilical vein endothelial cell culture}

Cells were maintained at $37^{\circ} \mathrm{C}$ in a humidified $5 \% \mathrm{CO}_{2}$ atmosphere. Human umbilical vein endothelial cells (HUVECs) from a pool of donors (Cell Applications, San Diego, CA) were cultured in endothelial growth medium (EGM; Cell Applications) with $10 \%$ FBS in $25-\mathrm{cm}^{2}$ flasks. Cells were not used beyond seven passages. Unless otherwise noted, all live cell imaging was performed on an Nikon Eclipse Ti inverted microscope (Nikon, Melville, NY) by using phase-contrast or fluorescence microscopy.

\section{HUVEC proliferation}

HUVECS were cultured in endothelial basal medium (EBM-2; Cell Applications) $\pm 10 \% \mathrm{CM}$ as indicated. In experiments where the exogenous effects of VEGF were evaluated, $2 \mathrm{ng} / \mathrm{mL}$ of recombinant human $\mathrm{VEGF}_{165}$ (rhVEGF; Thermo Fisher Scientific, Waltham, MA) was added to restore the VEGF content in D2KO-CM to that found in wildtype (WT)-CM. HUVEC number was determined by using Cell Counting Kit-8 (Dojindo Molecular Technologies, Gaithersberg, MD) 48 hours after plating as previously described (45).

\section{Assessment of mesh formation and branching}

To test the effects of CM collected from WT and D2KO $\mathrm{C} 2 \mathrm{C} 12$ cells on HUVEC angiogenic potential, mesh (tube) formation and branching were analyzed as previously described (45). Briefly, HUVECs $\left(2 \times 10^{4}\right.$ cells $\left./ \mathrm{mL}\right)$ were suspended in EBM-2 supplemented with 10\% CM from differentiated WT or D2KO C2C12 cells. HUVECs $(100 \mu \mathrm{L} /$ well) were seeded in a Matrigel-coated (Corning Incorporated Life Sciences, Corning, NY) 96-well plate and incubated for 2-4 hours. HUVECs were treated with $2 \mu \mathrm{M}$ Calcein AM Fluorescent Dye (Corning Incorporated Life Sciences) for 30 minutes and subsequently imaged on an inverted microscope at $10 \times$ by using phase-contrast microscopy or fluorescent microscopy. The number of branches, total branching length, number of meshes, and total mesh area were calculated by using the Angiogenesis Analyzer plugin for ImageJ.

\section{Scratch assay}

HUVECs were suspended in EGM, seeded at a density of $1 \times 10^{5}$ cells per well in a 12 -well plate, and allowed to attach overnight. The cell monolayer was scratched in a straight line by using a p200 pipet tip. HUVECs were washed once with EBM-2, then cultured in EBM-2 with $10 \%$ FBS and 10\% CM plus $2 \mathrm{ng} / \mathrm{mL}$ rhVEGF if indicated. To ensure that the same field was used during image acquisition, reference points were marked. During the 8-18 hour incubation period, the plate was imaged periodically at $10 \times$ by using phase-contrast microscope. Scratch area was measured by using ImageJ.

\section{Transwell migration assay}

HUVECs were suspended in EBM-2 at $1.5 \times 10^{5}$ cells $/ \mathrm{mL}$ and added to the upper chamber of a $6.5 \mathrm{~mm}$ transwell insert with $8.0 \mu \mathrm{m}$ polycarbonate membrane (Corning Incorporated Life Sciences). The lower chamber was filled with EBM-2 supplemented with $20 \% \mathrm{CM}$ collected from either differentiated WT or D2KO C2C12 cells. After three hours, HUVECs that had migrated through the membrane were stained with NucBlue live cell stain ReadyProbes reagent (Molecular Probes) and imaged at $20 \times$ by using a fluorescent microscope. For each condition, the cells present in seven randomly selected fields were counted.

\section{RNA extraction and real-time quantitative polymerase chain reaction}

RNA was extracted from $\mathrm{C} 2 \mathrm{C} 12$ cells, fluorescenceactivated cell sorting (FACS)-purified muscle stem cells, and whole muscle by using Trizol (Thermo Fisher Scientific) according to the manufacturer's instructions. Primers were synthesized by Invitrogen, and mouse cyclophilin-A was used as the internal reference gene. All primer sequences are listed in Supplementary Table S1. Reverse transcription was performed by using the high-capacity cDNA reverse transcription kit (Thermo Fisher Scientific), according to the manufacturer's instructions. Gene expression was detected by using SYBR Select Master Mix (Applied Biosystems, Waltham, MA) on the LightCycler II (Roche, Burlington, MA). The delta delta $\mathrm{Ct}$ method was used to calculate the fold change in gene expression compared with WT control (36).

\section{Chromatin immunoprecipitation}

Chromatin immunoprecipitation (ChIP) was performed as previously described. Briefly, C2C12 cells were fixed, lysed, and sonicated to obtain 200-1000 bp DNA fragments. Soluble chromatin was precleared by using $1 \mu \mathrm{g}$ of nonimmune immunoglobulin G (Calbiochem, Burlington, MA) and $30 \mu \mathrm{L}$ of Protein G Plus/Protein A Agarose suspension (Calbiochem) saturated with salmon sperm $(1 \mathrm{mg} / \mathrm{mL})$ and then incubated with $1 \mu \mathrm{g}$ of anti-TR $\alpha$ antibody (C3) (ab2743; Abcam, Cambridge, MA) (46-48). Bound DNA-protein complexes were eluted, cross-links were reversed, and samples were phenol-chloroform extracted and ethanol precipitated and used for real-time quantitative polymerase chain reaction.

\section{In silico promoter analysis}

Consensus TR binding sites (Matrix ID \# M00239) with a similarity of 0.73 or greater in the region from $1.5 \mathrm{~kb}$ upstream to $0.5 \mathrm{~kb}$ downstream of the transcription start site (TSS) of the mouse Vegfa gene were identified by using TFBIND (Supplementary Table S2) (49).

\section{Animals}

All animal studies were approved by the Institutional Animal Care and Use Committees of Brigham and Women's Hospital or University of Naples "Federico II." Mice were male and 8-14 weeks of age. Mice with a global deletion of the Dio2 gene (D2KO mice) were previously described and were backcrossed into a C57BL/6J background (20). The 
tibialis anterior (TA) muscle of mice was injured by an injection of $20 \mu \mathrm{L}$ of $10 \mu \mathrm{M}$ cardiotoxin as previously described, and TA was collected on days $1,3,5,7$, and 14 postinjury (21). T3-treated mice received $4 \mu \mathrm{g}$ of $\mathrm{T} 3$ in phosphate-buffered saline (PBS) by intraperitoneal injection (Sigma, St. Louis, MO), while control mice were injected with PBS alone. TA, soleus, and gastrocnemius muscles were collected 24 hours after treatment. Hypothyroidism was induced by treating mice with $0.1 \%$ methimazole and $1 \%$ $\mathrm{KClO}_{4}$ in drinking water for six weeks as described (46).

\section{Immunofluorescence}

TA and soleus muscles were frozen in dry ice-cooled isopentane and embedded in Tissue-Tek O.C.T (Sakura, Torrance, CA); $8 \mu \mathrm{m}$ sections were cut by using a cryostat. Muscle sections were permeabilized with $0.5 \%$ Triton $\mathrm{X}-100 / \mathrm{PBS}$ for 20 minutes. Antigen retrieval was performed by boiling in citrate buffer. Mouse antigen was blocked in anti-mouse Affinipure Fab fragment (Jackson ImmunoResearch, West Grove, PA) for one hour and incubated with primary antibodies at $4{ }^{\circ} \mathrm{C}$ overnight. Primary antibodies used include: Anti-CD31 (1:50, AF3628-SP; R\&D systems), antiPAX7 (1:50; DSHB, Iowa City, IA), and anti-VE-cadherin (1:100, AF1002; R\&D systems). Sections were incubated for one hour at room temperature with donkey anti-mouse Alexa Fluor 594 or donkey anti-goat Alexa Fluor 488 secondary antibodies (1:1000; Invitrogen). All wash steps were performed by using $0.3 \%$ Triton X-100 in PBS. Samples were mounted with Vectashield Mounting Medium with 4',6diamidino-2-phenylindole (Vector Laboratories, Burlingame, CA) and imaged with a Nikon H600L microscope by using a $40 \times$ objective (Nikon). Three fields per section were quantified by using ImageJ.

\section{Fluorescence-activated cell sorting}

Endothelial cells and muscle stem cells were isolated from TA as previously described (50). Briefly, the TA of WT and $\mathrm{D} 2 \mathrm{KO}$ mice were collected and digested in collagenase II $(75 \mathrm{U} / \mathrm{mL})$, followed by digestion in dispase II $(2.4 \mathrm{U} / \mathrm{mL}) /$ collagenase D (1.5 U/mL) (Sigma). After passing through a $40 \mu \mathrm{m}$ cell strainer, cells were stained for CD45 (1:500, phycoerythrin, 103106; Biolegend, San Diego, CA), CD34 (1:200, fluorescein isothiocyanate, 560238; BD Biosciences, San Jose, CA), CD31(1:500, PacBlue, 102422; Biolegend), Sca1 (1:200, APC, 122512; Biolegend), and $\alpha 7$-integrin (1:200, AF750, 75-0010-05; AbLab, Vancouver, British Columbia, Canada). FACS was performed by using a BD FACSAria II flow cytometer (BD Biosciences), and data were analyzed by using FlowJo software (FlowJo LLC, Ashland, OR). Muscle stem cells were identified as $\operatorname{lin}^{-} \mathrm{Sca}^{-} \alpha 7^{+}$, while endothelial cells were $\mathrm{CD} 45^{-} \mathrm{CD} 31^{+}$ $\mathrm{Sca}^{+} \mathrm{CD} 34^{\mathrm{dim}}(50,51)$.

\section{Statistical analysis}

Data are presented as mean \pm standard error of mean. Statistical analysis was performed by using GraphPad Prism 8.2 software (Graphpad, San Diego, CA), with $p<0.05$ being considered statistically significant. Details of analyses can be found in the figure legends. All cell-based experiments were repeated at least twice in duplicate with similar results unless otherwise indicated, while the $n$ of animal-based experiments is indicated in the figure legends.

\section{Results}

\section{Dio2 loss results in decreased VEGF during C2C12 differentiation}

Previous studies have shown in skeletal muscle after injury that there is significant crosstalk between muscle stem cells and other cell types in the muscle stem cell niche (28). We sought to determine whether Dio2 loss alters the expression of factors that are important for satellite cell-endothelial interactions. To test this, we used the $\mathrm{C} 2 \mathrm{C} 12$ murine myoblast cell line, which can be differentiated to mature myotubes on serum withdrawal (21). We also employed a C2C12 cell line that we created in which the Dio2 gene was disrupted by using CRISPR/Cas9 (D2KO C2C12) (26). As expected, differentiation of $\mathrm{C} 2 \mathrm{C} 12$ cells to myotubes resulted in a marked increase in Dio2 expression (Supplementary Fig. S1) (21). There was no significant difference between WT and $\mathrm{D} 2 \mathrm{KO} \mathrm{C} 2 \mathrm{C} 12$ cells in the expression of previously described factors involved in myoblast-endothelial cell crosstalk during differentiation such as Met, Igfrl, Fgfrl, or Fgfr3, while Pdgfra was slightly increased in D2KO C2C12 cells after five days of differentiation (Supplementary Fig. S2) (29). However, we did find that gene expression for VEGF (Vegfa), a potent mediator of angiogenesis, was markedly different. Vegfa gene expression was increased by 3.0-fold after four days of differentiation in WT C2C12 cells (Fig. 1A). In contrast, after four days of differentiation, Vegfa expression in D2KO C2C12 was only 1.7-fold of basal level, and $46 \%$ of WT levels (Fig. 1A). VEGF in the culture medium was increased by 6.1 -fold after three days of differentiation, but this increase was significantly blunted in D2KO C2C12 cells, which were $45 \%$ of WT levels at the same time (Fig. 1B).

\section{Role of T3 in Vegfa expression}

The increases in Dio2 during muscle stem cell differentiation lead to increased T4 to T3 conversion, which potentiates muscle stem cell differentiation (21); thus, we explored the relationship between T3 and Vegfa expression. To initially assess the T3-responsiveness of the Vegfa gene in vitro, we differentiated WT C2C12 cells for four days in media containing serum that was resin-stripped to remove T3 and then supplemented with various doses of replacement T3. Addition of $1 \mathrm{nM} \mathrm{T3}$ increased Vegfa expression by $46 \%$ (Fig. 2A). A similar induction was observed when cells were T3-treated for 24 hours after differentiation (Supplementary Fig. S3). Further, T3 supplementation of D2KO C2C12 cells, differentiated under normal conditions, partially rescued Vegfa expression, leading to a $56 \%$ increase above D2KO C2C12 levels (Fig. 2B).

In vivo, mice that were rendered hypothyroid by treating them with TH synthesis inhibitors in their drinking water had a dramatic 18-fold decrease in Vegfa expression in their gastrocnemius muscle (Fig. 2C). When euthyroid mice were treated by an intraperitoneal injection of $4 \mu \mathrm{g}$ of T3, Vegfa expression tended to be slightly increased (1.2-fold, $p=0.11)$ in their gastrocnemius muscle 24 hours later (Fig. 2D), while other T3-responsive marker genes such as $U c p 3$ and $\mathrm{Hr}$ were 

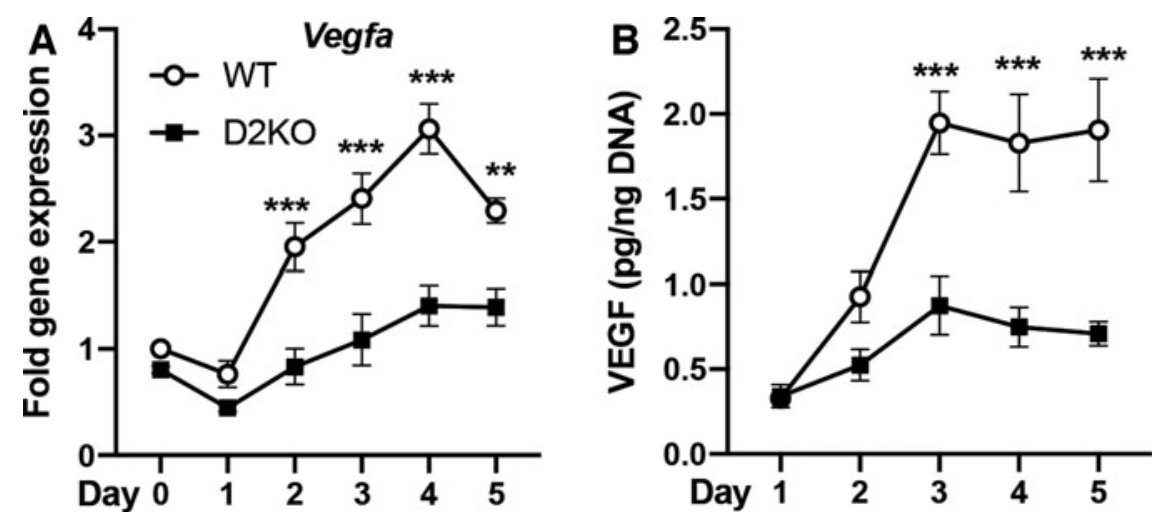

FIG. 1. Vegfa mRNA and VEGF protein during WT and D2KO C2C12 cell differentiation. Differentiation was initiated on day 0 , and cells were collected at the indicated time points. (A) Vegfa mRNA expression was measured by qPCR, while (B) culture medium was collected to measure VEGF levels by enzyme-linked immunosorbent assay. VEGF was normalized to DNA content. Statistical analysis was performed by two-way ANOVA followed by Sidak's multiple-comparison test to compare WT with D2KO at each time point. Values shown are mean \pm SEM, $* * p<0.01$, $* * * p<0.001$. ANOVA, analysis of variance; SEM, standard error of mean; VEGF, vascular endothelial growth factor; qPCR, quantitative polymerase chain reaction; WT, wildtype.
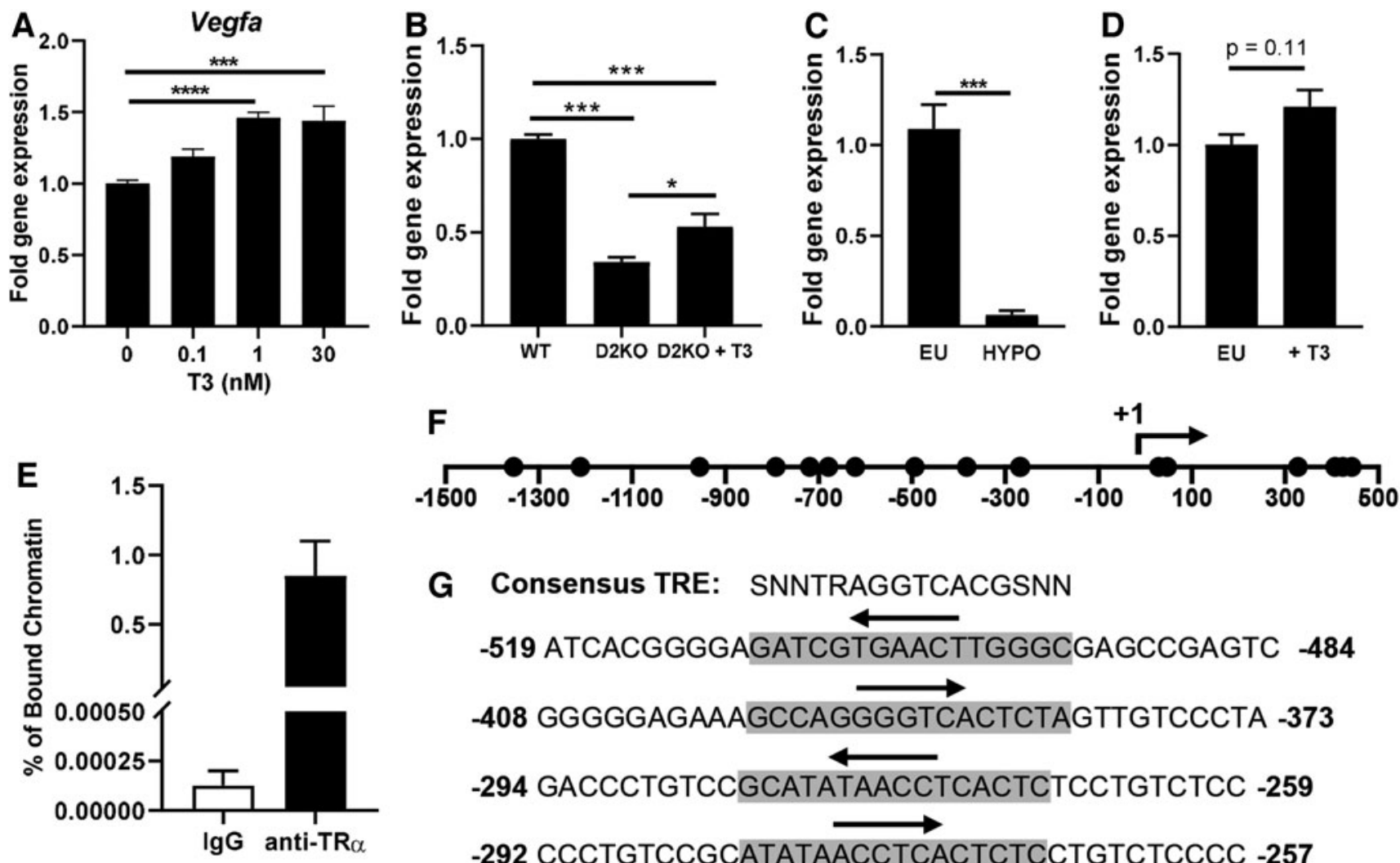

G Consensus TRE: SNNTRAGGTCACGSNN -519 ATCACGgGagATCGTGACTTGGGGaGCGAGTC -484 -408 GGgGGAGAAGCCAGGGGTCACTCTAGTTGTCCCTA $-\mathbf{3 7 3}$ -294 GACCCTGTCCGCATATAACCTCACTCTCCTGTCTCC -259 $\mathbf{- 2 9 2}$ CCCTGTCCGCATATAACCTCACTCTCCTGTCTCCCC $\mathbf{- 2 5 7}$

FIG. 2. Vegfa is a T3 target gene. Vegfa expression was measured by qPCR in (A) WT C2C12 cells differentiated in THfree differentiation medium with the indicated amount of T3 for four days and (B) WT and D2KO C2C12 cells differentiated $\pm 30 \mathrm{nM} T 3$ for five days. Vegfa expression in the gastrocnemius muscle of mice that were (C) hypothyroid or (D) treated with $4 \mu \mathrm{g}$ T3 for 24 hours ( $n=3-6 /$ group). (E) ChIP was performed on WT C2C12 cells by using anti-TR $\alpha$, and the percentage (\%) of TR $\alpha$-bound chromatin enriched for Vegfa in WT C2C12 cells was determined by using qPCR $(n=2)$. (F) Potential TR binding sites identified by in silico analysis of the Vegfa gene are indicated by circles with the TSS at +1 . (G) Sequence of the first four consensus TR binding sites identified upstream of the Vegfa TSS. The sequence matching the consensus site is highlighted in gray, while the region corresponding to the conserved AGGTCA is indicated by an arrow. Values shown are mean \pm SEM. $* p<0.05, * * * p<0.001$ by one-way ANOVA followed by Tukey's multiple comparison test $(\mathbf{A}, \mathbf{B})$ or unpaired Student's $t$-test $(\mathbf{C}, \mathbf{D}, \mathbf{F})$. TSS, transcription start site; ChIP, chromatin immunoprecipitation; TH, thyroid hormone; TR, thyroid hormone receptor; T3, 3,3',5-triiodothyronine. 
increased 3.9-fold and 4.7-fold, respectively, confirming the effectiveness of this treatment (data not shown).

$\mathrm{TR} \alpha$ was previously reported to be the predominant TR isoform in skeletal muscle (52). ChIP, using a TR $\alpha$ antibody to determine whether Vegfa is a direct T3-target gene, indicated substantial enrichment of $\mathrm{TR} \alpha$ binding (Fig. 2E). In silico analysis of the Vegfa gene (from $1.5 \mathrm{~kb}$ upstream to $0.5 \mathrm{~kb}$ downstream of the TSS) identified 17 potential consensus TR binding sites (Fig. 2F and Supplementary Table S2). The first four sites upstream of the TSS are shown in Figure 2G. Taken together, our data strongly suggest that the Vegfa gene is a direct T3 target and that the upregulation of Vegfa during differentiation requires $\mathrm{T} 4$ to $\mathrm{T} 3$ conversion by $\mathrm{DIO} 2$.

\section{Assessment of the consequences of Dio2 loss in $\mathrm{C} 2 \mathrm{C} 12$ cells on endothelial cell function}

After four days of differentiation, the amount of VEGF in WT C2C12 CM was 2.5-fold that of D2KO C2C12 cells (Fig. 1B). To assess the impact of the different amounts of VEGF produced by WT and D2KO C2C12 cells on endothelial cell function, we incubated HUVECs with either WT or D2KO CM. Initially, we assessed the effects of WT and D2KO CM supplementation on HUVEC growth. We found that the supplementation of HUVEC basal growth medium with WT-CM significantly increased HUVEC cell number 1.4-fold after 48 hours (Fig. 3A). In contrast, the addition of D2KO-CM slightly increased HUVECs cell number 1.1-fold, which was further augmented to 1.3 -fold by exogenous rhVEGF addition (Fig. 3A). Addition of rhVEGF alone increased cell number by 1.1 -fold (data not shown).

We also assessed the effects of WT- or D2KO-CM addition on HUVEC angiogenesis in vitro by quantitating branching and the formation of tube-like mesh structures. When HUVECs were supplemented with D2KO-CM versus WT$\mathrm{CM}$, there was no change in the absolute number of branches formed, but total branch length was decreased by $17 \%$, while the number of tube-like mesh structures and total mesh area were decreased by $39 \%$ and $85 \%$, respectively (Fig. 3B-F).

Effects on endothelial cell migration were evaluated by using the scratch test. The percentage of wound closure was $21 \%$ less in HUVECs cultured with D2KO-CM than that with WT-CM (Fig. 3G, H). We found that the number of HUVECs that migrated through the transwell membrane to D2KO-CM was $66 \%$ less compared with migration toward WT-CM (Fig. 3I, J). Exogenous rhVEGF addition to D2KO-CM significantly increased HUVEC migration to levels approaching that of WT-CM (Fig. 3I, J).

\section{D2KO mice have lower Vegfa expression and fewer endothelial cells in soleus muscle}

To extend the in vitro results, we examined the effects of Dio2 loss in vivo in the skeletal muscle of mice with a global disruption of the Dio2 gene (D2KO mice). We focused on changes in the soleus muscle, since DIO2 is highest in this slow-twitch skeletal muscle (53). Vegfa was significantly decreased by $28 \%$ in D2KO mice (Fig. 4A). Expression of the VEGF receptor, VEGFR2 $(K d r)$, was decreased by $27 \%$ while the expression of the decoy VEGF receptor that can antagonize VEGF-action VEGFR1 (Flt1) (54) was not significantly changed (Fig. 4A). Expression of PCG-1 $\alpha$ (Pparg$c l a$ ), an upstream regulator of $V e g f a$, was also significantly decreased by $31 \%$ in D2KO soleus muscle (55). Expression of the endothelial cell marker CD31 (Pecam1) was decreased by $25 \%$, while VE-cadherin ( $C d h 5)$, a major endothelial adhesion molecule that controls endothelial cell junctions and blood vessel formation (56), was decreased by $23 \%$. Expression of the muscle stem cell marker Pax7 was not significantly different. Immunostaining for CD31 was decreased by $48 \%$ and while VE-cadherin trended toward being decreased (an 18\% reduction, $p=0.06$ ), indicating that there were significantly fewer endothelial cells in $\mathrm{D} 2 \mathrm{KO}$ soleus and a trend toward less blood vessel formation (Fig. 4B, C and Supplementary Fig. S4). Staining for the muscle stem cell marker PAX7 was decreased by $60 \%$ in D2KO soleus muscle under basal conditions (Fig. 4B, D). Taken together, our in vivo data corroborate our in vitro findings that Dio2 loss results in reduced Vegfa expression and endothelial cell number.

\section{Response of D2KO skeletal muscle to injury}

To determine how Dio2 loss affects Vegfa and endothelial cell response during skeletal muscle regeneration, we injured the TA muscle of WT and D2KO mice by an injection of cardiotoxin (a component of snake venom). Vegfa expression and endothelial cell number were evaluated at time points that are associated with activation (1 day postinjury [dpi]), proliferation ( 3 and $5 \mathrm{dpi}$ ), differentiation ( 5 and $7 \mathrm{dpi}$ ), and maturation (14 dpi) of skeletal muscle stem cells after injury (57). Vegfa expression was slightly decreased in the uninjured D2KO TA at 0 dpi (Fig. 5A). After injury, Vegfa expression initially declined in the damaged tissue, reaching a nadir at $3 \mathrm{dpi}$, and it then steadily increased over time; however, there was no difference between WT and D2KO mice (Fig. 5A). A similar pattern of expression was observed for the endothelial cell marker Pecam1, and the muscle stem cell marker Pax7, and there was also no difference between WT and D2KO mice (Fig. 5B, C). We also observed no differences in the expression of Dio3 between WT and D2KO mice at any time after injury, suggesting no compensatory changes in this TH-inactivating enzyme at the transcriptional level (data not shown). Immunostaining of WT and D2KO muscle indicated that CD31 tended to be lower $(24 \%$, $p=0.08)$ in D2KO muscle at $7 \mathrm{dpi}$ (Fig. 5D, E), while staining for VE-cadherin was not different between either genotype at any time point after injury (Supplementary Fig. S5). Staining for the muscle stem cell marker PAX7 was also significantly lower by $49 \%$ in D2KO 14 days after injury (Fig. 5D, F).

$V e g f a$ can also be expressed in other cell types in skeletal muscle besides muscle stem cells $(58,59)$. Thus, we evaluated the specific contribution of muscle stem cells by measuring Vegfa levels in FACS-purified muscle stem cells. Vegfa expression was significantly decreased by $88 \%$ in D2KO muscle stem cells five days after injury, while there was a trend toward a decrease seven days after injury (83\% decrease, $p=0.14$ ) (Fig. 5G). Flow cytometry analysis of injured tissues indicated that there were $36 \%$ fewer endothelial cells seven days after injury in D2KO mice (Fig. 5H).

Blood vessel loss after injury results in hypoxia that stimulates Vegfa expression leading to increased angiogenesis (54). We further explored whether Dio2 loss would affect this mechanism. WT and D2KO C2C12 cells were differentiated for 48 hours under $1 \% \mathrm{O}_{2}$, and Vegfa expression 

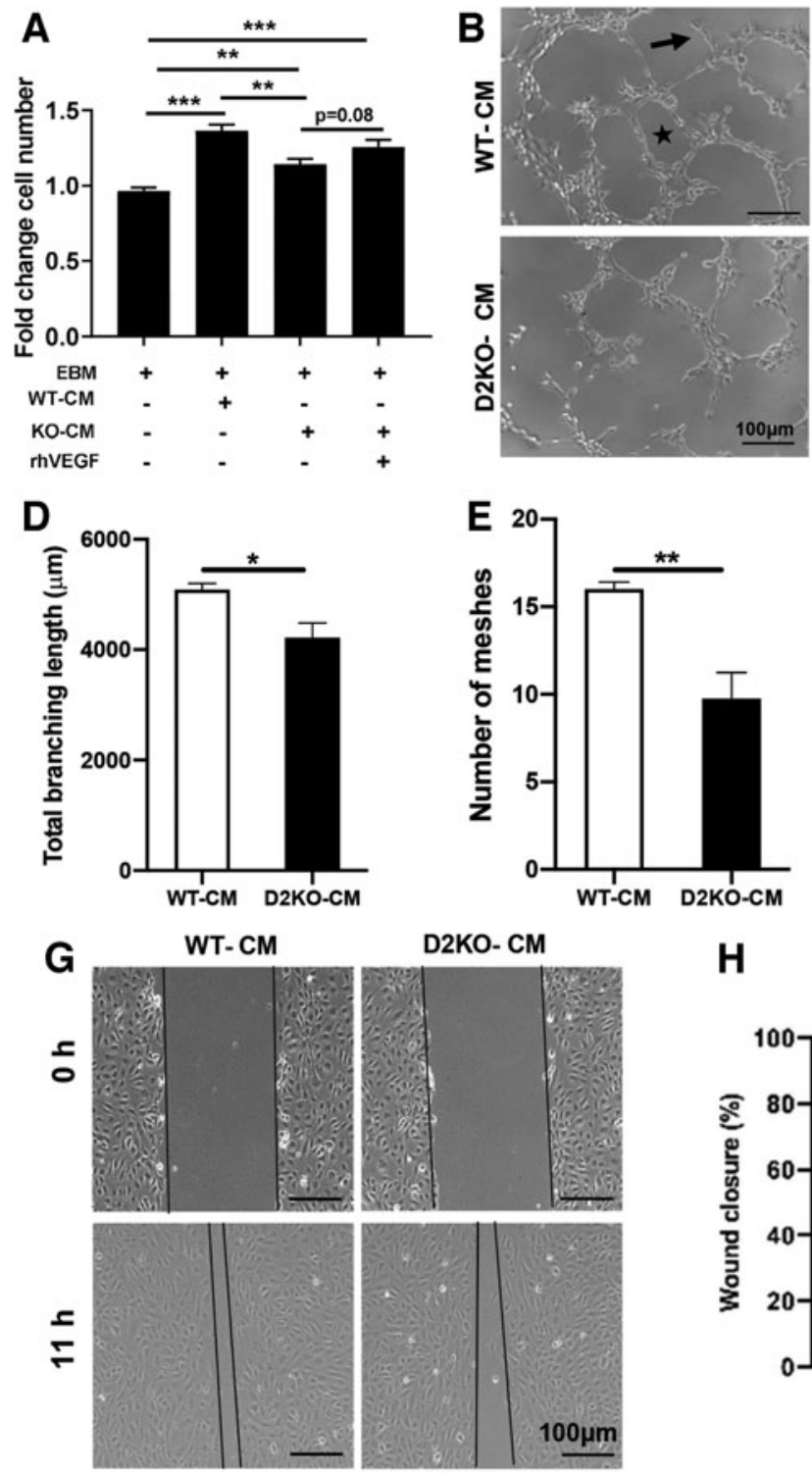

H
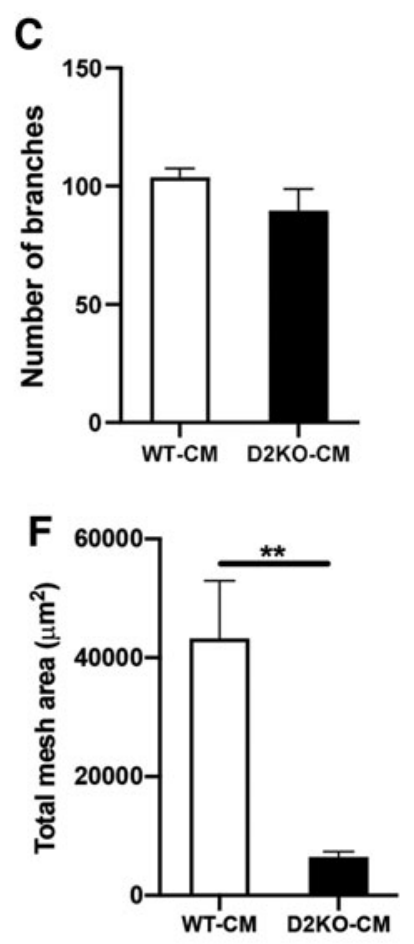
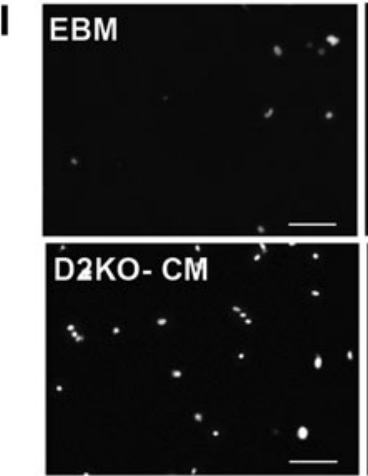

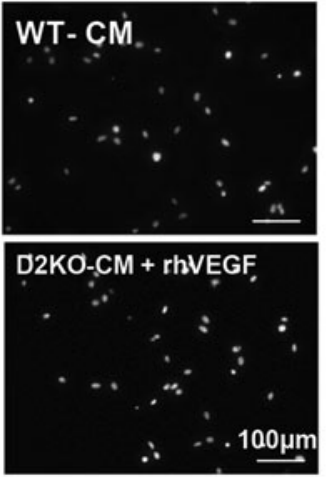

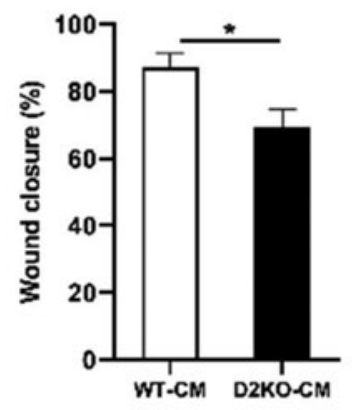

$\mathbf{J}$

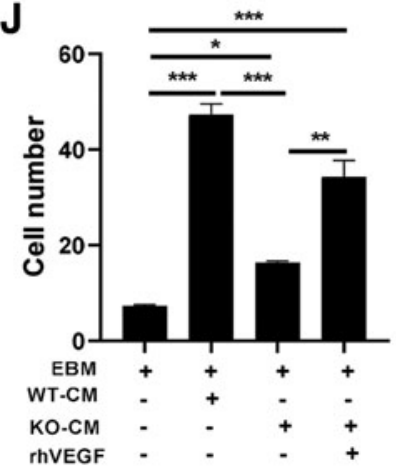

FIG. 3. Consequences of Dio2 loss in C2C12 cells on endothelial cell function. CM was collected from WT or D2KO C2C12 differentiated for four days and used to treat HUVECs. (A) Cell number after 48 hours of growth in EBM plus the indicated additions, $(\mathbf{B}-\mathbf{F})$ branch (indicated by arrow) and mesh (indicated by a star) formation were quantitated. $(\mathbf{G}, \mathbf{H})$ Confluent HUVECs were scratched with a pipet tip, and the area remaining after regrowth \pm supplementation with either WT- or D2KO$\mathrm{CM}$ (indicated between black lines) was determined after 11 hours. (I, J) HUVEC migration through a transwell insert toward a lower chamber containing WT-or $\mathrm{D} 2 \mathrm{KO}-\mathrm{CM}$ was determined. Cells were stained with NucBlue live cell stain. Values shown are mean \pm SEM. $* p<0.05$, ** $p<0.01$, $* * * p<0.001$ by one-way ANOVA followed by Tukey's multiplecomparison test $(\mathbf{A}, \mathbf{J})$ or unpaired Student's $t$-test (C-F, H). Dio2, type 2 deiodinase; $\mathrm{CM}$, conditioned medium; HUVEC, human umbilical vein endothelial cell; EBM, endothelial basal medium. was evaluated. Hypoxia led to a 1.8-fold induction of Vegfa in WT C2C12 cells and a 2.2-fold induction in D2KO C2C12 cells when compared with the basal levels for each cell type (Fig. 5I). Nevertheless, the overall response to hypoxia was slightly lower by $19 \%$ in D2KO C2C12 cells when compared with the response of WT C2C12 cells. Treatment with the hypoxia mimetic $\mathrm{CoCl}_{2}$ showed comparable results (Supplementary Fig. S6). Under these conditions, Dio3 expression was barely detectable, and thus it is unlikely that changes in $\mathrm{TH}$ inactivation are contributing to these results.

\section{Discussion}

This study defines a role for DIO2-mediated T3 production in muscle stem cell-endothelial cell crosstalk during skeletal muscle regeneration. We found that Vegfa is a target of 
A

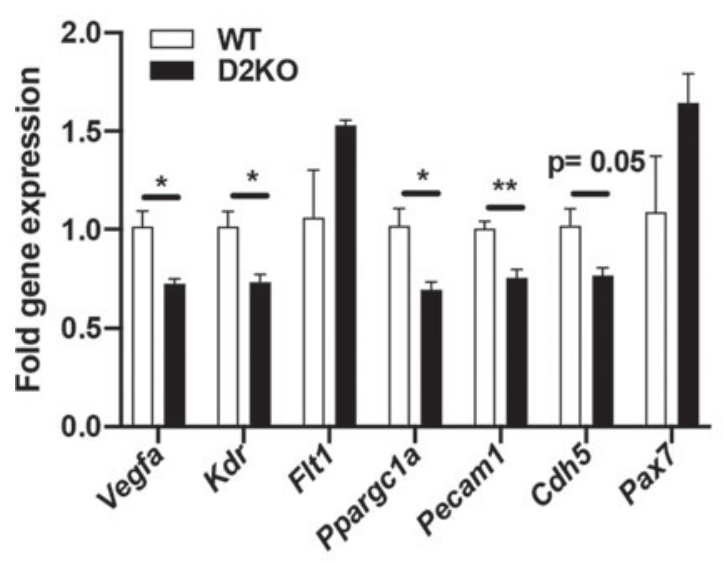

B
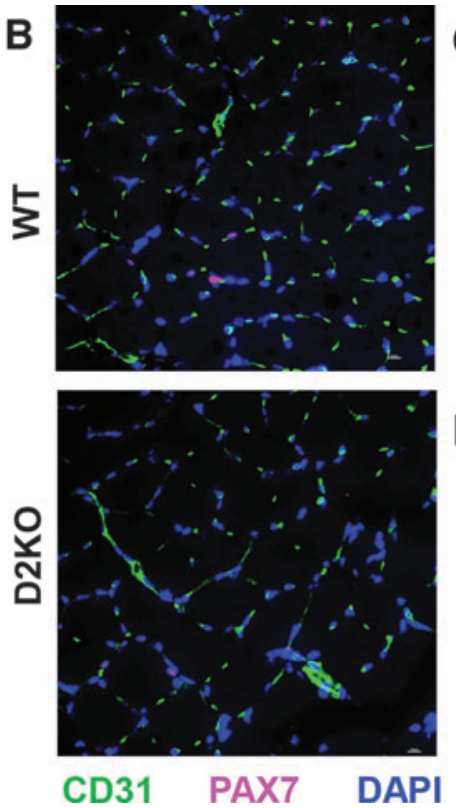
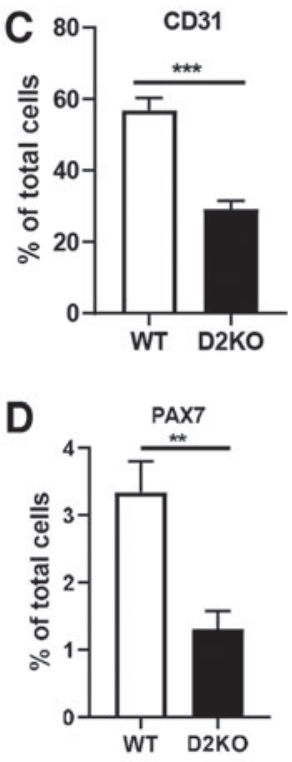

FIG. 4. Expression of Vegfa and related genes and endothelial cell number in WT and D2KO soleus. (A) Expression of the indicated genes was measured by qPCR in WT and D2KO soleus $(n=3-6$ mice/group). (B-D) Immunostaining and quantification of WT and D2KO soleus with CD31 (green), and PAX7 (magenta). Nuclei were stained blue with DAPI. Mean \pm SEM are shown, ${ }^{*} p<0.05,{ }^{* *} p<0.01,{ }^{* * *} p<0.001$ by unpaired Student's $t$-test. DAPI, $4^{\prime}, 6$-diamidino-2phenylindole.

genomic T3 action in the muscle stem cell, and that increases in Dio2 in this cell type potentiate Vegfa expression during differentiation. Dio2 loss leads to decreased Vegfa mRNA and secreted VEGF protein levels, altering the downstream effects on endothelial cells both in vitro and in vivo. Although it has been previously shown that a Dio2-mediated increase in $\mathrm{T} 3$ in satellite cells is required for differentiation to mature myotubes (21), our current study also demonstrates that this increase can indirectly impact other cell types in the muscle stem cell niche by regulating the production of secreted growth factors.

A disruption of the Dio2 gene results in decreased Vegfa mRNA expression in $\mathrm{C} 2 \mathrm{C} 12$ cells during differentiation. Our data indicate that this change in expression is likely a direct effect of diminished DIO2-mediated $\mathrm{T} 3$ production, since we have identified TR-binding sites and numerous potential TH response elements in the Vegfa promoter by using ChIP and in silico analysis, respectively. Although no classical direct repeats with four base pair spacing (DR-4) arrangements of consensus binding half-sites were identified (1), it is possible that other weaker binding sites may contribute to the functionality of these regions. In vivo studies further indicated that Vegfa gene expression was markedly T3 responsive in the hypothyroid to euthyroid range. Our data supporting a direct genomic role for T3 in Vegfa expression are in agreement with other studies in which TR $\alpha$ knockdown in osteoblasts decreased the T3-dependent induction of Vegfa (60).

We cannot discount indirect effects of T3 on Vegfa expression that could also be affected by Dio2 loss, as there are many T3-responsive pathways that converge to regulate the Vegfa gene. For example, Dio2 loss results in decreased expression of the T3-responsive PGC- $1 \alpha$ gene in skeletal muscle $(26,61,62)$. Vegfa expression is also regulated by PGC- $1 \alpha$, and thus lower levels of this coactivator may contribute to its decreased expression (55). HIF- $1 \alpha$, a potent regulator of Vegfa during hypoxia, is also $\mathrm{T} 3$ responsive $(36,39,40)$. Although the overall levels of Vegfa expression after hypoxia were lower in $\mathrm{D} 2 \mathrm{KO} \mathrm{C} 2 \mathrm{C} 12$ cells as a result of lower levels of basal expression, there was no difference in the Vegfa response to hypoxia between WT and D2KO C2C12 cells, indicating that Dio2 loss does not impair this pathway.

Non-genomic T3 action via integrin $\alpha \mathrm{v} \beta 3$ also can induce Vegfa expression $(35,63)$; however, single-cell sequencing data from the Tabula Muris database indicate that muscle stem cells do not express integrin $\beta 3$, thus suggesting that this mechanism is not relevant in the muscle stem cell (59). Nevertheless, D2KO muscle has less T3 derived from T4, and lower T3 content $(20,25)$. Further, D2KO mice have elevated serum T4 levels (24). Thus, we cannot rule out that alterations in T3 and/or T4 in this mouse model could lead to effects on muscle endothelial cells and vascularization through integrins present in other cell types.

Our data indicate that under basal conditions, the number of endothelial cells and $\mathrm{Pax} 7^{+}$satellite cells were decreased in D2KO soleus muscle. In contrast, we observed no differences in the number of either cell type in the TA muscle. Soleus, a slow oxidative muscle, is highly $\mathrm{T} 3$ responsive, and it is dramatically affected by the loss of either TR or Dio2 but whether this directly affects muscle stem cell number or endothelial cell number is unknown $(26,64,65)$. Nevertheless, Dio2 expression increases dramatically in the TA after injury, and muscle regeneration is impaired in D2KO mice (21). Our studies identified additional defects in the repair process of $\mathrm{D} 2 \mathrm{KO}$ mice, with the number of endothelial cells in their injured muscle being significantly lower at seven days after injury. However, this difference was no longer apparent by 14 days after injury, indicating that there is 
A

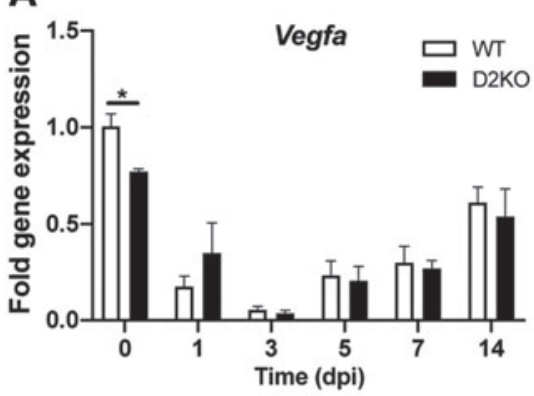

D
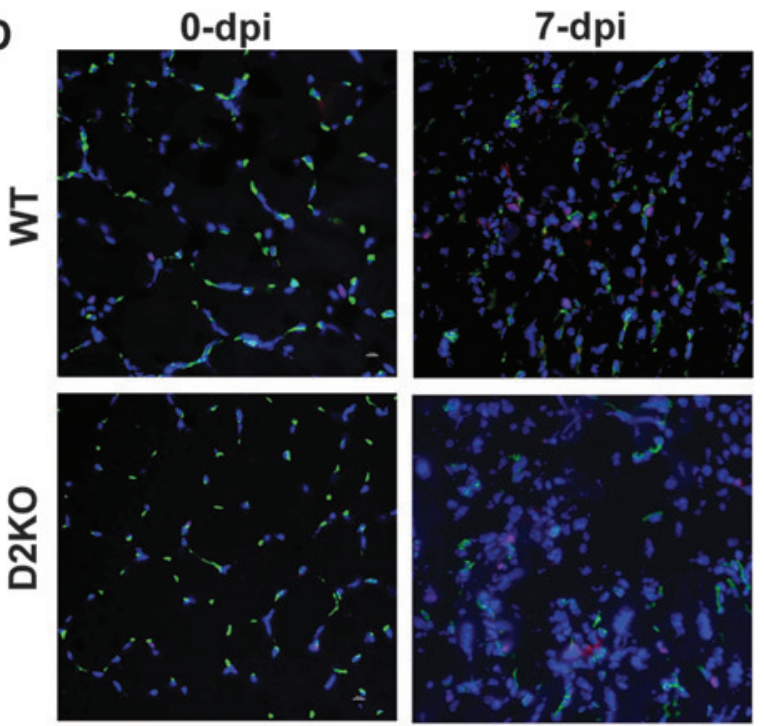

G

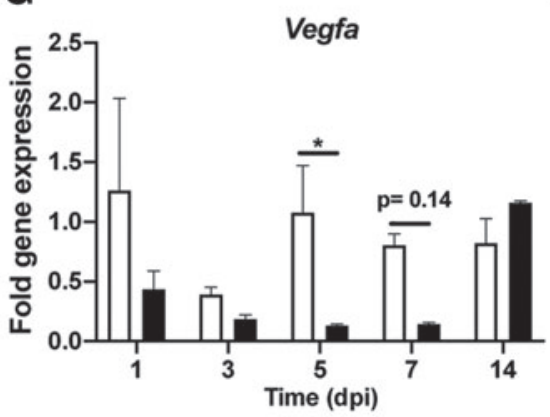

B
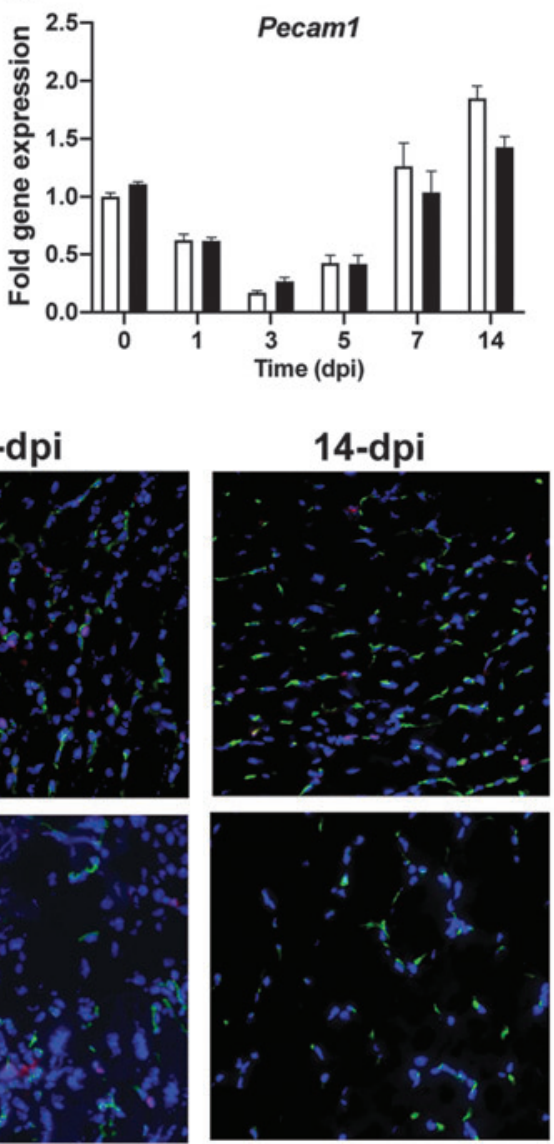

H

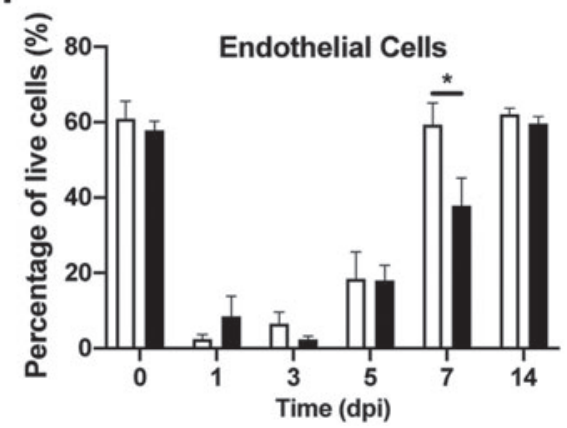

C
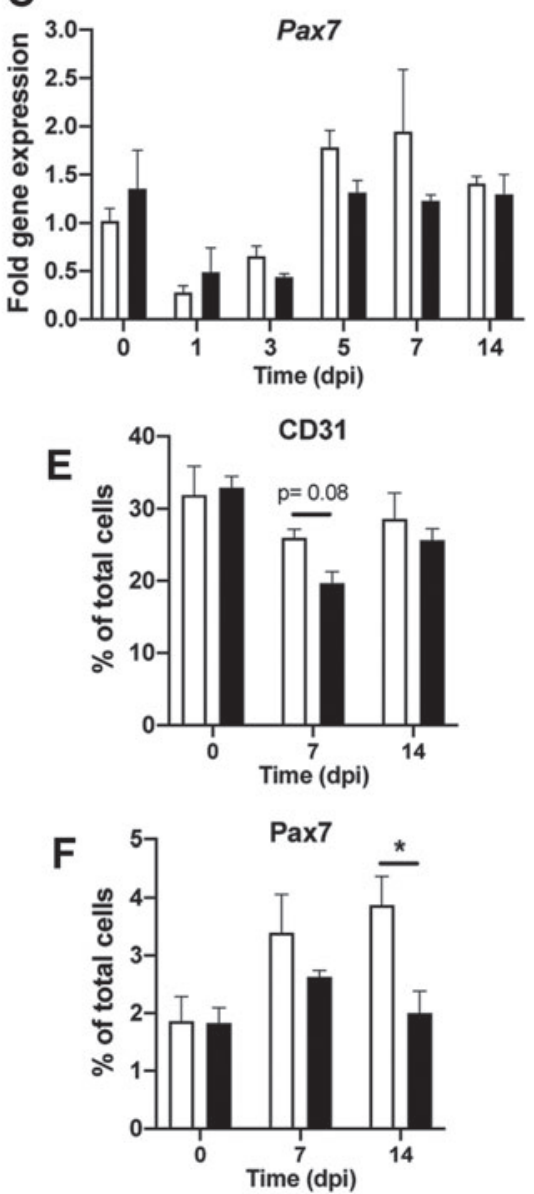

I

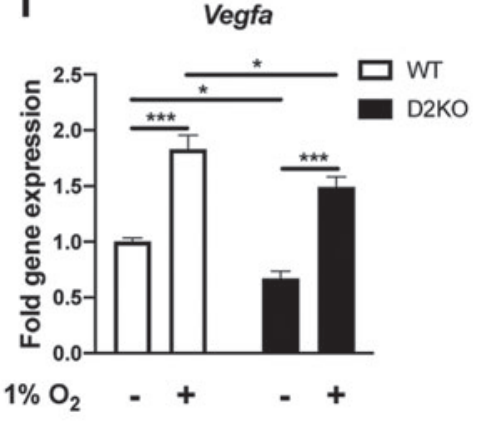

FIG. 5. The role of Dio2 in Vegfa response to TA injury and hypoxia. WT and D2KO mice were injured by cardiotoxin injection in the TA and collected at the indicated dpi. (A-C) mRNA expression levels were measured via qPCR in whole TA ( $n=3-7$ mice/group). (D-F) Immunostaining and quantitation of WT and D2KO TA muscle after injury with CD31 (green), and PAX7 (magenta). Nuclei were stained blue with DAPI. (G) FACS-purified muscle stem cells (lin ${ }^{-} S c a 1^{-} \alpha 7^{+}$) were collected, and Vegfa expression levels were measured via $\mathrm{qPCR}$. (H) Endothelial cells $\left(\mathrm{CD} 45^{-} \mathrm{CD} 31^{+} \mathrm{Sca} 1^{+}\right.$) were analyzed by FACS and are shown as the \% of total live cells. (I) WT and D2KO C2C12 were differentiated for four days under $20 \%$ or $1 \% \mathrm{O}_{2}$, and Vegfa expression levels were measured. Values shown are mean \pm SEM. $* p<0.05$, $* * * p<0.001$ by two-way ANOVA followed by Sidak's multiple-comparison test. dpi, days postinjury; FACS, fluorescence-activated cell sorting; TA, tibialis anterior.

delay, but not overall impairment, in the re-establishment of endothelial cell number in D2KO mice. Despite this difference, there was no change between WT and D2KO Vegfa expression levels in the injured whole TA. However, Vegfa expression was lower in FACS-isolated D2KO muscle stem cells on days 5 and 7 after injury. This discrepancy could be due to other cell types, such as mesenchymal stem cells and endothelial cells, which also express Vegfa, not being affected by loss of Dio2.

Previous findings indicate that the close proximity between muscle stem cells and endothelial cells facilitates paracrine interactions between these two cell types (31), supporting the concept that VEGF supplied by muscle stem cells may preferentially impact the function of adjacent endothelial 
cells. In agreement with this, our in vitro data showed that treatment of HUVECs with CM from a myoblast cell line without Dio2 led to less proliferation, migration, and capillary network formation, which could be ameliorated by exogenous VEGF treatment. This further strengthens the premise that Dio2-expressing muscle stem cells provide secreted factors, which can affect endothelial cell function. Although these studies have focused on changes in Vegfa, we cannot rule out that Dio2 loss may lead to alterations in other as-yet-to-be-determined factors.

We observed that the number of $\mathrm{Pax} 7^{+}$muscle stem cells was lower in the $\mathrm{D} 2 \mathrm{KO}$ soleus muscle under basal conditions when compared with WT; however, the number of muscle stem cells was not different in the TA. Although we do not know the cause of this difference at this time, we speculate that it may be related to differences in fiber type composition between the two muscles. In this regard, DIO2 activity is higher in slow oxidative muscle than fast glycolytic muscle (53), and soleus is composed primarily of slow oxidative fibers, while the TA has a mixed fiber type (66). After injury, we found there were less $\mathrm{Pax} 7^{+}$muscle stem cells D2KO TA at $14 \mathrm{dpi}$, consistent with a delayed regeneration of $\mathrm{D} 2 \mathrm{KO}$ muscle. Of note, the decrease in $\operatorname{Pax} 7^{+}$cell number in $\mathrm{D} 2 \mathrm{KO}$ mice is not correlated with a decrease in $\operatorname{Pax} 7$ mRNA, suggesting that D2KO muscle stem cells may express more of this transcription factor. Alternatively, the PAX7 protein is regulated both translationally and posttranslationally, and this may account for the differences observed $(67,68)$.

These results suggest that the manipulation of T3 levels, via modulation of Dio2, could be used to alter Vegfa expression and VEGF levels to regulate angiogenesis therapeutically. For example, various strategies to increase VEGF-action have been shown to improve vascularity and muscle function in a mouse model of muscular dystrophy, suggesting that upregulation of Dio2 could be useful in this disease (69-71). Inhibition of VEGF is also a major strategy to decrease vascularity of tumors (54). Since increases in Dio2 have been recently associated with the progression of squamous cell carcinomas to advanced stages (47), our data raise the possibility that an inhibition of Dio2 might decrease Vegfa and vascularity of these tumors, leading to lower invasiveness and metastases. Taken together, these possibilities further reinforce the potential of Dio2 as a therapeutic target.

In conclusion, we have found that Dio2 facilitates communication between muscle stem cells and endothelial cells during muscle regeneration by the T3-dependent regulation of Vegfa in the muscle stem cell. Muscle stem cells also interact with other cells in the muscle stem cell niche, such as fibroadipogenic progenitors, macrophages, $\mathrm{T}$ regulatory cells, pericytes, and fibroblasts, under both basal conditions and during muscle repair (28). Future studies will further define how Dio2 in the muscle stem cell affects interactions with these other cell types, highlighting the importance of spatiotemporal regulation of T3 delivery by Dio2 in skeletal muscle.

\section{Acknowledgments}

The authors would like to thank Drs. Warner Simonides and Duo Zhang for helpful discussions.

\section{Author Disclosure Statement}

No competing financial interests exist.

\section{Funding Information}

This work has been supported by R01DK044128 from National Institute of Diabetes and Digestive and Kidney Diseases (NIDDK) to A.M.Z. and P.R.L. X.A. is supported by China Scholarship Council, and A.O.-W. is supported by a training grant T32DK007529 from NIDDK. D.E.H. is supported, in part, by a grant from the American Heart Association (D700382). This study was financed in part by the Coordenação de Aperfeiçoamento de Pessoal de Nível Superior-Brasil (Capes)_finance Code 001 that supported S.M.W.

\section{Supplementary Material}

Supplementary Figure S1

Supplementary Figure S2

Supplementary Figure S3

Supplementary Figure S4

Supplementary Figure S5

Supplementary Figure S6

Supplementary Table S1

Supplementary Table S2

\section{References}

1. Vella KR, Hollenberg AN 2017 The actions of thyroid hormone signaling in the nucleus. Mol Cell Endocrinol 458: $127-135$.

2. Hammes SR, Davis PJ 2015 Overlapping nongenomic and genomic actions of thyroid hormone and steroids. Best Pract Res Clin Endocrinol Metab 29:581-593.

3. Köhrle J 2019 The colorful diversity of thyroid hormone metabolites. Eur Thyroid J 8:115-129.

4. Bianco AC, Dumitrescu A, Gereben B, Ribeiro MO, Fonseca TL, Fernandes GW, Bocco BMLC 2019 Paradigms of dynamic control of thyroid hormone signaling. Endocr Rev 40:1000-1047.

5. Salvatore D, Simonides WS, Dentice M, Zavacki AM, Larsen PR 2014 Thyroid hormones and skeletal musclenew insights and potential implications. Nat Rev Endocrinol 10:206-214.

6. Visser WE, Heemstra KA, Swagemakers SM, Ozgür Z, Corssmit EP, Burggraaf J, van Ijcken WF, van der Spek PJ, Smit JW, Visser TJ 2009 Physiological thyroid hormone levels regulate numerous skeletal muscle transcripts. J Clin Endocrinol Metab 94:3487-3496.

7. Khaleeli AA, Edwards RH 1984 Effect of treatment on skeletal muscle dysfunction in hypothyroidism. Clin Sci (Lond) 66:63-68.

8. Mier A, Brophy C, Wass JA, Besser GM, Green M 1989 Reversible respiratory muscle weakness in hyperthyroidism. Am Rev Respir Dis 139:529-533.

9. Gallo D, Piantanida E, Veronesi G, Lai A, Sassi L, Lombardi V, Masiello E, Premoli P, Bianconi E, Cusini C, Rosetti S, Tanda ML, Toniolo A, Ferrario M, Bartalena L 2017 Physical performance in newly diagnosed hypothyroidism: a pilot study. J Endocrinol Invest 40:1099-1106.

10. Spira D, Buchmann N, Demuth I, Steinhagen-Thiessen E, Völzke H, Ittermann T 2019 Association of thyroid function with handgrip strength: data from the study of health in pomerania and the berlin aging study II. Thyroid 29:1220-1226. 
11. Brennan MD, Powell C, Kaufman KR, Sun PC, Bahn RS, Nair KS 2006 The impact of overt and subclinical hyperthyroidism on skeletal muscle. Thyroid 16:375-380.

12. Khaleeli AA, Gohil K, McPhail G, Round JM, Edwards RH 1983 Muscle morphology and metabolism in hypothyroid myopathy: effects of treatment. J Clin Pathol 36:519-526.

13. Brennan MD, Coenen-Schimke JM, Bigelow ML, Nair KS 2006 Changes in skeletal muscle protein metabolism and myosin heavy chain isoform messenger ribonucleic acid abundance after treatment of hyperthyroidism. J Clin Endocrinol Metab 91:4650-4656.

14. Taylor DJ, Rajagopalan B, Radda GK 1992 Cellular energetics in hypothyroid muscle. Eur J Clin Invest 22: 358-365.

15. McDaniel HG, Pittman CS, Oh SJ, DiMauro S 1977 Carbohydrate metabolism in hypothyroid myopathy. Metabolism 26:867-873.

16. Lin RT, Liu CK, Tai CT, Lai CL 2000 Hypothyroid myopathy-pathological and ultrastructural study. Kaohsiung J Med Sci 16:68-75.

17. Monzani F, Caraccio N, Siciliano G, Manca L, Murri L, Ferrannini E 1997 Clinical and biochemical features of muscle dysfunction in subclinical hypothyroidism. J Clin Endocrinol Metab 82:3315-3318.

18. Sindoni A, Rodolico C, Pappalardo MA, Portaro S, Benvenga S 2016 Hypothyroid myopathy: a peculiar clinical presentation of thyroid failure. Review of the literature. Rev Endocr Metab Disord 17:499-519.

19. Lankhaar JA, de Vries WR, Jansen JA, Zelissen PM, Backx FJ 2014 Impact of overt and subclinical hypothyroidism on exercise tolerance: a systematic review. Res Q Exerc Sport 85:365-389.

20. Marsili A, Tang D, Harney JW, Singh P, Zavacki AM, Dentice M, Salvatore D, Larsen PR 2011 Type II iodothyronine deiodinase provides intracellular 3,5,3'-triiodothyronine to normal and regenerating mouse skeletal muscle. Am J Physiol Endocrinol Metab 301:E818-E824.

21. Dentice M, Marsili A, Ambrosio R, Guardiola O, Sibilio A, Paik JH, Minchiotti G, DePinho RA, Fenzi G, Larsen PR, Salvatore D 2010 The FoxO3/type 2 deiodinase pathway is required for normal mouse myogenesis and muscle regeneration. J Clin Invest 120:4021-4030.

22. Werneck-de-Castro JP, Fonseca TL, Ignacio DL, Fernandes GW, Andrade-Feraud CM, Lartey LJ, Ribeiro MB, Ribeiro MO, Gereben B, Bianco AC 2015 Thyroid hormone signaling in male mouse skeletal muscle is largely independent of D2 in myocytes. Endocrinology 156:3842-3852.

23. Bloise FF, van der Spek AH, Surovtseva OV, OrtigaCarvalho TM, Fliers E, Boelen A 2016 Differential effects of sepsis and chronic inflammation on diaphragm muscle fiber type, thyroid hormone metabolism, and mitochondrial function. Thyroid 26:600-609.

24. Schneider MJ, Fiering SN, Pallud SE, Parlow AF, St Germain DL, Galton VA 2001 Targeted disruption of the type 2 selenodeiodinase gene (DIO2) results in a phenotype of pituitary resistance to T4. Mol Endocrinol 15:21372148.

25. Bárez-López S, Bosch-García D, Gómez-Andrés D, Pulido-Valdeolivas I, Montero-Pedrazuela A, Obregon MJ, Guadaño-Ferraz A 2014 Abnormal motor phenotype at adult stages in mice lacking type 2 deiodinase. PLoS One 9:e103857.

26. Carmody C, Ogawa-Wong AN, Martin C, Luongo C, Zuidwijk M, Sager B, Petersen T, Roginski Guetter A,
Janssen R, Wu EY, Bogaards S, Neumann NM, Hau K, Marsili A, Boelen A, Silva JE, Dentice M, Salvatore D, Wagers AJ, Larsen PR, Simonides WS, Zavacki AM 2019 A global loss of Dio2 leads to unexpected changes in function and fiber types of slow skeletal muscle in male mice. Endocrinology 160:1205-1222.

27. Brack AS, Rando TA 2012 Tissue-specific stem cells: lessons from the skeletal muscle satellite cell. Cell Stem Cell 10:504-514.

28. Wosczyna MN, Rando TA 2018 A muscle stem cell support group: coordinated cellular responses in muscle regeneration. Dev Cell 46:135-143.

29. Christov C, Chrétien F, Abou-Khalil R, Bassez G, Vallet G, Authier FJ, Bassaglia Y, Shinin V, Tajbakhsh S, Chazaud B, Gherardi RK 2007 Muscle satellite cells and endothelial cells: close neighbors and privileged partners. Mol Biol Cell 18:1397-1409.

30. Latroche C, Weiss-Gayet M, Muller L, Gitiaux C, Leblanc P, Liot S, Ben-Larbi S, Abou-Khalil R, Verger N, Bardot P, Magnan M, Chrétien F, Mounier R, Germain S, Chazaud B 2017 Coupling between myogenesis and angiogenesis during skeletal muscle regeneration is stimulated by restorative macrophages. Stem Cell Rep 9:2018-2033.

31. Verma M, Asakura Y, Murakonda BSR, Pengo T, Latroche C, Chazaud B, McLoon LK, Asakura A 2018 Muscle satellite cell cross-talk with a vascular niche maintains quiescence via VEGF and notch signaling. Cell Stem Cell 23:530-543.e539.

32. Risau W 1997 Mechanisms of angiogenesis. Nature 386: 671-674.

33. Ferrara N, Houck K, Jakeman L, Leung DW 1992 Molecular and biological properties of the vascular endothelial growth factor family of proteins. Endocr Rev 13: 18-32.

34. Bryan BA, Walshe TE, Mitchell DC, Havumaki JS, SaintGeniez M, Maharaj AS, Maldonado AE, D’Amore PA 2008 Coordinated vascular endothelial growth factor expression and signaling during skeletal myogenic differentiation. Mol Biol Cell 19:994-1006.

35. Luidens MK, Mousa SA, Davis FB, Lin HY, Davis PJ 2010 Thyroid hormone and angiogenesis. Vascul Pharmacol 52: 142-145.

36. An X, Liao G, Chen Y, Luo A, Liu J, Yuan Y, Li L, Yang L, Wang H, Liu F, Yang G, Yi S, Li Y, Cheng J, Lu Y 2019 Intervention for early diabetic nephropathy by mesenchymal stem cells in a preclinical nonhuman primate model. Stem Cell Res Ther 10:363.

37. Schmohl KA, Müller AM, Wechselberger A, Rühland S, Salb N, Schwenk N, Heuer H, Carlsen J, Göke B, Nelson PJ, Spitzweg C 2015 Thyroid hormones and tetrac: new regulators of tumour stroma formation via integrin $\alpha \mathrm{v} \beta 3$. Endocr Relat Cancer 22:941-952.

38. Cayrol F, Díaz Flaqué MC, Fernando T, Yang SN, Sterle HA, Bolontrade M, Amorós M, Isse B, Farías RN, Ahn H, Tian YF, Tabbò F, Singh A, Inghirami G, Cerchietti L, Cremaschi GA 2015 Integrin $\alpha \mathrm{v} \beta 3$ acting as membrane receptor for thyroid hormones mediates angiogenesis in malignant T cells. Blood 125:841-851.

39. Moeller LC, Dumitrescu AM, Walker RL, Meltzer PS, Refetoff S 2005 Thyroid hormone responsive genes in cultured human fibroblasts. J Clin Endocrinol Metab 90: 936-943.

40. Moretto FC, De Sibio MT, Luvizon AC, Olimpio RM, de Oliveira M, Alves CA, Conde SJ, Nogueira CR 2016 
Triiodothyronine (T3) induces HIF1A and TGFA expression in MCF7 cells by activating PI3K. Life Sci 154:52-57.

41. Dhole B, Gupta S, Venugopal SK, Kumar A 2018 Triiodothyronine stimulates VEGF expression and secretion via steroids and HIF- $1 \alpha$ in murine Leydig cells. Syst Biol Reprod Med 64:191-201.

42. Chen J, Ortmeier SB, Savinova OV, Nareddy VB, Beyer AJ, Wang D, Gerdes AM 2012 Thyroid hormone induces sprouting angiogenesis in adult heart of hypothyroid mice through the PDGF-Akt pathway. J Cell Mol Med 16:27262735.

43. Samuels HH, Stanley F, Casanova J 1979 Depletion of L-3,5,3'-triiodothyronine and L-thyroxine in euthyroid calf serum for use in cell culture studies of the action of thyroid hormone. Endocrinology 105:80-85.

44. Bensaid S, Fabre C, Fourneau J, Cieniewski-Bernard C 2019 Impact of different methods of induction of cellular hypoxia: focus on protein homeostasis signaling pathways and morphology of $\mathrm{C} 2 \mathrm{C} 12$ skeletal muscle cells differentiated into myotubes. J Physiol Biochem 75:367-377.

45. An X, Li L, Chen Y, Luo A, Ni Z, Liu J, Yuan Y, Shi M, Chen B, Long D, Cheng J, Lu Y 2016 Mesenchymal stem cells ameliorated glucolipotoxicity in HUVECs through TSG-6. 17:483.

46. Sagliocchi S, Cicatiello AG, Di Cicco E, Ambrosio R, Miro C, Di Girolamo D, Nappi A, Mancino G, De Stefano MA, Luongo C, Raia M, Ogawa-Wong AN, Zavacki AM, Paladino S, Salvatore D, Dentice M 2019 The thyroid hormone activating enzyme, type 2 deiodinase, induces myogenic differentiation by regulating mitochondrial metabolism and reducing oxidative stress. Redox Biol 24: 101228.

47. Miro C, Di Cicco E, Ambrosio R, Mancino G, Di Girolamo D, Cicatiello AG, Sagliocchi S, Nappi A, De Stefano MA, Luongo C, Antonini D, Visconte F, Varricchio S, Ilardi G, Del Vecchio L, Staibano S, Boelen A, Blanpain C, Missero C, Salvatore D, Dentice M 2019 Thyroid hormone induces progression and invasiveness of squamous cell carcinomas by promoting a ZEB-1/E-cadherin switch. Nat Commun 10:5410.

48. Raychaudhuri N, Thamotharan S, Srinivasan M, Mahmood S, Patel MS, Devaskar SU 2014 Postnatal exposure to a high-carbohydrate diet interferes epigenetically with thyroid hormone receptor induction of the adult male rat skeletal muscle glucose transporter isoform 4 expression. J Nutr Biochem 25:1066-1076.

49. Tsunoda T, Takagi T 1999 Estimating transcription factor bindability on DNA. Bioinformatics 15:622-630.

50. Judson RN, Low M, Eisner C, Rossi FM 2017 Isolation, culture, and differentiation of fibro/adipogenic progenitors (FAPs) from skeletal muscle. Methods Mol Biol 1668: 93-103.

51. Ieronimakis N, Hays A, Reyes M 2012 Bone marrowderived cells do not engraft into skeletal muscle microvasculature but promote angiogenesis after acute injury. Exp Hematol 40:238-249.e3.

52. Milanesi A, Lee JW, Yang A, Liu YY, Sedrakyan S, Cheng SY, Perin L, Brent GA 2017 Thyroid hormone receptor alpha is essential to maintain the satellite cell niche during skeletal muscle injury and sarcopenia of aging. Thyroid 27: 1316-1322.

53. Marsili A, Ramadan W, Harney JW, Mulcahey M, Castroneves LA, Goemann IM, Wajner SM, Huang SA, Zavacki AM, Maia AL, Dentice M, Salvatore D, Silva JE,
Larsen PR 2010 Type 2 iodothyronine deiodinase levels are higher in slow-twitch than fast-twitch mouse skeletal muscle and are increased in hypothyroidism. Endocrinology 151:5952-5960.

54. Apte RS, Chen DS, Ferrara N 2019 VEGF in signaling and disease: beyond discovery and development. Cell 176: 1248-1264.

55. Arany Z, Foo SY, Ma Y, Ruas JL, Bommi-Reddy A, Girnun G, Cooper M, Laznik D, Chinsomboon J, Rangwala SM, Baek KH, Rosenzweig A, Spiegelman BM 2008 HIFindependent regulation of VEGF and angiogenesis by the transcriptional coactivator PGC-1alpha. Nature 451:10081012.

56. Harris ES, Nelson WJ 2010 VE-cadherin: at the front, center, and sides of endothelial cell organization and function. Curr Opin Cell Biol 22:651-658.

57. Gary GA, Antony ML, Gary DJ 2016 Cardiotoxin induced injury and skeletal muscle regeneration. In: Kyba M (ed) Skeletal Muscle Regeneration in the Mouse: Methods and Protocols. Vol 1460. Springer Science + Business Media, New York, pp 61-72.

58. Ferrara N, Gerber HP, LeCouter J 2003 The biology of VEGF and its receptors. Nat Med 9:669-676.

59. Consortium TM 2018 Single-cell transcriptomics of 20 mouse organs creates a Tabula Muris. Nature 562:367-372.

60. Li L, Li M, Pang Y, Wang J, Wan Y, Zhu C, Yin Z 2019 Abnormal thyroid hormone receptor signaling in osteoarthritic osteoblasts regulates microangiogenesis in subchondral bone. Life Sci 239:116975.

61. Bocco BM, Louzada RA, Silvestre DH, Santos MC, Anne-Palmer E, Rangel IF, Abdalla S, Ferreira AC, Ribeiro MO, Gereben B, Carvalho DP, Bianco AC, Werneckde-Castro JP 2016 Thyroid hormone activation by type 2 deiodinase mediates exercise-induced peroxisome proliferatoractivated receptor-gamma coactivator-1alpha expression in skeletal muscle. J Physiol 594:5255-5269.

62. Lesmana R, Sinha RA, Singh BK, Zhou J, Ohba K, Wu Y, Yau WW, Bay BH, Yen PM 2016 Thyroid hormone stimulation of autophagy is essential for mitochondrial biogenesis and activity in skeletal muscle. Endocrinology 157:23-38.

63. Schmohl KA, Mueller AM, Dohmann M, Spellerberg R, Urnauer S, Schwenk N, Ziegler SI, Bartenstein P, Nelson PJ, Spitzweg C 2019 Integrin $\alpha v \beta 3$-mediated effects of thyroid hormones on mesenchymal stem cells in tumor angiogenesis. Thyroid 29:1843-1857.

64. Yu F, Göthe S, Wikström L, Forrest D, Vennström B, Larsson L 2000 Effects of thyroid hormone receptor gene disruption on myosin isoform expression in mouse skeletal muscles. Am J Physiol Regul Integr Comp Physiol 278: R1545-R1554.

65. Johansson C, Lunde PK, Gothe S, Lannergren J, Westerblad H 2003 Isometric force and endurance in skeletal muscle of mice devoid of all known thyroid hormone receptors. J Physiol 547:789-796.

66. Bloemberg D, Quadrilatero J 2012 Rapid determination of myosin heavy chain expression in rat, mouse, and human skeletal muscle using multicolor immunofluorescence analysis. PLoS One 7:e35273.

67. Hulin JA, Nguyen TD, Cui S, Marri S, Yu RT, Downes M, Evans RM, Makarenkova H, Meech R 2016 Barx2 and Pax7 regulate axin2 expression in myoblasts by interaction with $\beta$-catenin and chromatin remodelling. Stem Cells 34: 2169-2182. 
68. González N, Moresco JJ, Cabezas F, de la Vega E, Bustos F, Yates JR, Olguín HC 2016 Ck2-dependent phosphorylation is required to maintain $\mathrm{Pax} 7$ protein levels in proliferating muscle progenitors. PLoS One 11:e0154919.

69. Deasy BM, Feduska JM, Payne TR, Li Y, Ambrosio F, Huard J 2009 Effect of VEGF on the regenerative capacity of muscle stem cells in dystrophic skeletal muscle. Mol Ther 17:1788-1798.

70. Borselli C, Storrie H, Benesch-Lee F, Shvartsman D, Cezar C, Lichtman JW, Vandenburgh HH, Mooney DJ 2010 Functional muscle regeneration with combined delivery of angiogenesis and myogenesis factors. Proc Natl Acad Sci U S A 107:3287-3292.

71. Verma M, Shimizu-Motohashi Y, Asakura Y, Ennen J, Bosco J, Zou Z, Fong G-H, Josiah S, Keefe D, Asakura A
2019 Inhibition of FLT1 ameliorates muscular dystrophy phenotype by increased vasculature in a mouse model of Duchenne muscular dystrophy. PLoS Genet 15:e1008468.

Address correspondence to: Ann Marie Zavacki, PhD Division of Endocrinology, Diabetes, and Hypertension Department of Medicine Brigham and Women's Hospital Boston, MA 02115

USA

E-mail: azavacki@rics.bwh.harvad.edu 